\title{
Com os professores visitadores, a escola vai à família
}

\author{
ISA MARIA F. ROSA GUARÁ*
}

\section{O Programa de Interação Família Escola de Taboão da}

Serra, um município de 225 mil habitantes na Grande São Paulo, ganhou destaque e visibilidade nacional por seu caráter inovador e por seus resultados. Desenvolvido pela Secretaria de Educação da Prefeitura Municipal de Taboão da Serra desde 2005, o Programa, bastante conhecido como Programa dos Professores Visitadores recebeu o Prêmio Objetivo de Desenvolvimento do Milênio 2007 oferecido pelo Programa das Nações Unidas para o Desenvolvimento (PNUD) e pelo governo brasileiro para as melhores práticas voltadas à construção de um mundo melhor.

Hoje adotado como política pública, o Programa conseguiu ser ousado na prática pedagógica, criando uma ponte entre a família e a escola sem diluir suas especificidades ou confundir papéis. Neste sentido, reconhece que "cabe às escolas a tarefa de desenvolver habilidades e competências, construindo as áreas de saber consideradas fundamentais para o convívio social, cultural e à prática da cidadania" e que cabe à família "o acolhimento a seus filhos num ambiente estável, provedor e afetivo". Essa definição ajuda a estabelecer a parceria entre as instituições família e escola, compreendendo as diferenças e reconhecendo as características de cada instância e fazendo as pontes "sem perder de vista o objetivo de melhoria qualitativa no ensino"(SMETS, 2007). ${ }^{1}$

Ester Grossi (2001), ${ }^{2}$ enfatiza a necessidade desta clareza de papéis entre escola e família, lembrando que as tarefas complexas da aprendizagem devem ser exigidas da escola que, de modo profissional, responsável e competente se organiza para este fim. Os pais devem ser apoiados e orientados para que garantam um ambiente de estímulo à aprendizagem e de afeto e segurança para que a criança possa aprender e se desenvolver como pessoa.

\footnotetext{
* ISA Maria F. R. Guará é pedagoga, doutora e mestre em Serviço Social (PUC-SP) e pós-graduada em Psicopedagogia; professora da UNIBAN, assessora do NECA e coordenadora editorial dos Cadernos Cenpec.
}

Desde seu início, mais de 20 mil famílias foram visitadas pelos professores, o que vem permitindo uma intensa participação de pais no processo educativo com resultados muito positivos em relação ao rendimento escolar. A experiência tem favorecido a ampliação efetiva do conhecimento sobre a realidade sociofamiliar dos alunos e a introdução de novas estratégias para alcançar uma boa aprendizagem para todos. ${ }^{3}$

O fracasso escolar, como diz Mario Cartella, ${ }^{4}$ é um pedagocídio. Evitá-lo, lembra o autor, exige considerar tanto as condições extra-escolares, quanto as intra-escolares, evitando preconceitos e discriminações.

Portanto, a visita dos professores a casa dos alunos é algo planejado com cuidado e seriedade para que tenha significado. Segundo a Secretaria Municipal, as visitas ocorrem fora do horário escolar e os professores participantes do Programa trabalham com hipóteses e objetivos visando:

- “identificar no ambiente familiar as raízes das dificuldades de aprendizagem de um aluno, por exemplo, eventuais traumas de crescimento e desenvolvimento físico e emocional;

- buscar maior parceria dos pais no processo de desenvolvimento educacional dos filhos;

- esclarecer os pais sobre a metodologia de ensino adotado pela Escola, suas características e suas atividades;

- compreender melhor as condições de vida da família e ajustar as metodologias educacionais à essa realidade".

Se, em geral, os movimentos da sociedade civil que trazem a educação como bandeira não lograram, ainda, resultados animadores na aprendizagem dos alunos e na efetiva responsabilização social e comunitária pela melhoria da educação, o exemplo de Taboão da Serra mostra que a iniciativa de aproximação que parte da escola e do sistema educacional local pode ter efeitos muito positivos. 


\section{Programa de Interação Família Escola: resultados das ações articuladas em torno do Programa}

\begin{tabular}{ll}
\hline DESAFIos & RESPOSTAS \\
Melhoria da & Instituição de Grupos de Apoio Pedagógico para crianças com \\
Aprendizagem & dificuldades de aprendizagem, no contra-turno escolar. \\
& Implantação de Laboratórios de Aprendizagem nas escolas \\
& para diagnóstico e orientação dos problemas de desenvol- \\
& vimento escolar.
\end{tabular}

Ampliação de oportunidades educacionais para a comunidade

Oferta de Cursos de Informática e de Inglês para a Comunidade nos períodos noturnos e aos finais de semana.

Ampliação da oferta de vagas para Educação de Jovens e Adultos.

Oferta de atividades culturais para alunos e familiares por intermédio do Programa Fazendo Arte na Escola.

Ampliação da rede de proteção social
Articulação com os programas das Secretarias de Saúde e Assistência Social, com objetivo de enfrentar problemas do ambiente familiar e de saúde.

\section{RESULTADOS}

Duas mil crianças e jovens atendidos. Diagnósticos e orientações educacionais específicas para 140 alunos.
Inclusão de portadores de necessidades educacionais especiais
Criação de equipe multidisciplinar, constituída de médico pediatra, psicólogos, professores especializados, com objetivo de apoiar os docentes das escolas, com especial atenção às crianças com necessidades especiais de aprendizagem.
Mais de 10 mil jovens e adultos atendidos. Dois mil alunos

Cinco mil pessoas beneficiadas

\section{2 encaminhamentos}

292 alunos de inclusão freqüentando as escolas municipais.

Fonte: Programa de Interação Família Escola - Documento Básico de Orientação - SMETS.

Mesmo que algumas pesquisas mostrem que o background familiar é importante para o desempenho escolar, é preciso reconhecer que a escola ainda tem uma grande possibilidade de fazer a diferença.

\section{Como funciona?}

Embora os professores não sejam obrigados a participar do Programa, há a adesão voluntária da maioria dos professores. A prefeitura oferece um pró-labore para cada professor que visitar um aluno e sua família. A visita é feita durante a semana ou nos finais de semana. A coordenação do programa relata que o contato entre os pais ou responsáveis e os professores tem sido tranqüilo e a conversa sobre o desenvolvimento do aluno e seu aproveitamento escolar agrega informações sobre os aspectos mais diversos da vida familiar que podem favorecer o estudo dos alunos. Os dados sobre a realidade dos alunos são consolidados num relatório e discutidos na escola com a equipe pedagógica para que sejam planejadas novas abordagens educativas e eventuais encaminhamentos para que o aluno seja beneficiado.

\section{Impacto positivo no desempenho dos alunos}

As primeiras avaliações diagnósticas promovidas pela Secretaria de Educação da cidade com os alunos cujos professores participam do programa indicaram resultados altamente positivos. O Ministério da Educação (MEC) também confirmou o êxito dos estudantes da cidade. Segundo dados do Índice de Desenvolvimento da Educação Básica (Ideb), divulgados em junho de 2007, a cidade teve um aumento de $14,3 \%$, nos anos finais da educação básica (de $5^{\text {a à }} 8^{\underline{a}}$ séries), com a média de 4,8 , quando a previsão do MEC era de que Taboão da Serra só atingiria essa meta em 2012. Nos anos iniciais ( $\mathrm{da}_{1}$ - à $4^{\mathrm{a}}$ séries), o município também teve um crescimento expressivo, de 8,9\%, com a média de 4,9, acima da média nacional, que é de 4,2.

Certamente, o Programa de Interação Família Escola de Taboão da Serra ainda tem muitos desafios a enfrentar, mas já se pode perceber, nesta iniciativa, o cumprimento do artigo 57 do Estatuto da Criança e do Adolescente - ECA, que indica a necessidade de o sistema escolar buscar novas propostas pedagógicas, visando à inclusão educacional e à articulação entre o mundo da vida e o mundo do conhecimento.

\section{NOTA}

1 Secretaria Municipal de Educação de Taboão da Serra. 2007. Programa Interação Família Escola: ampliação e fortalecimento de uma iniciativa de êxito. Disponível na Internet: 〈http://200.198.62.75/dia2-4.ppt〉. Acesso em: 12 de janeiro de 2009.

2 Ester Pillar Grossi, Zero Hora, 25/04/2001 - Porto Alegre, RS. A família na escola.

3 No site da Secretaria Municipal de Educação de Taboão da Serra, pode-se acessar o documento básico de orientação sobre o Programa. Ver em 〈http://www.educataboao.com.br/familiaescola.pdf〉.

4 CORTELLA, M. S. A Escola e o conhecimento - fundamentos epistemológicos e políticos. São Paulo: Cortez, 1998. p.137-160 (Instituto Paulo Freire nํ5). 


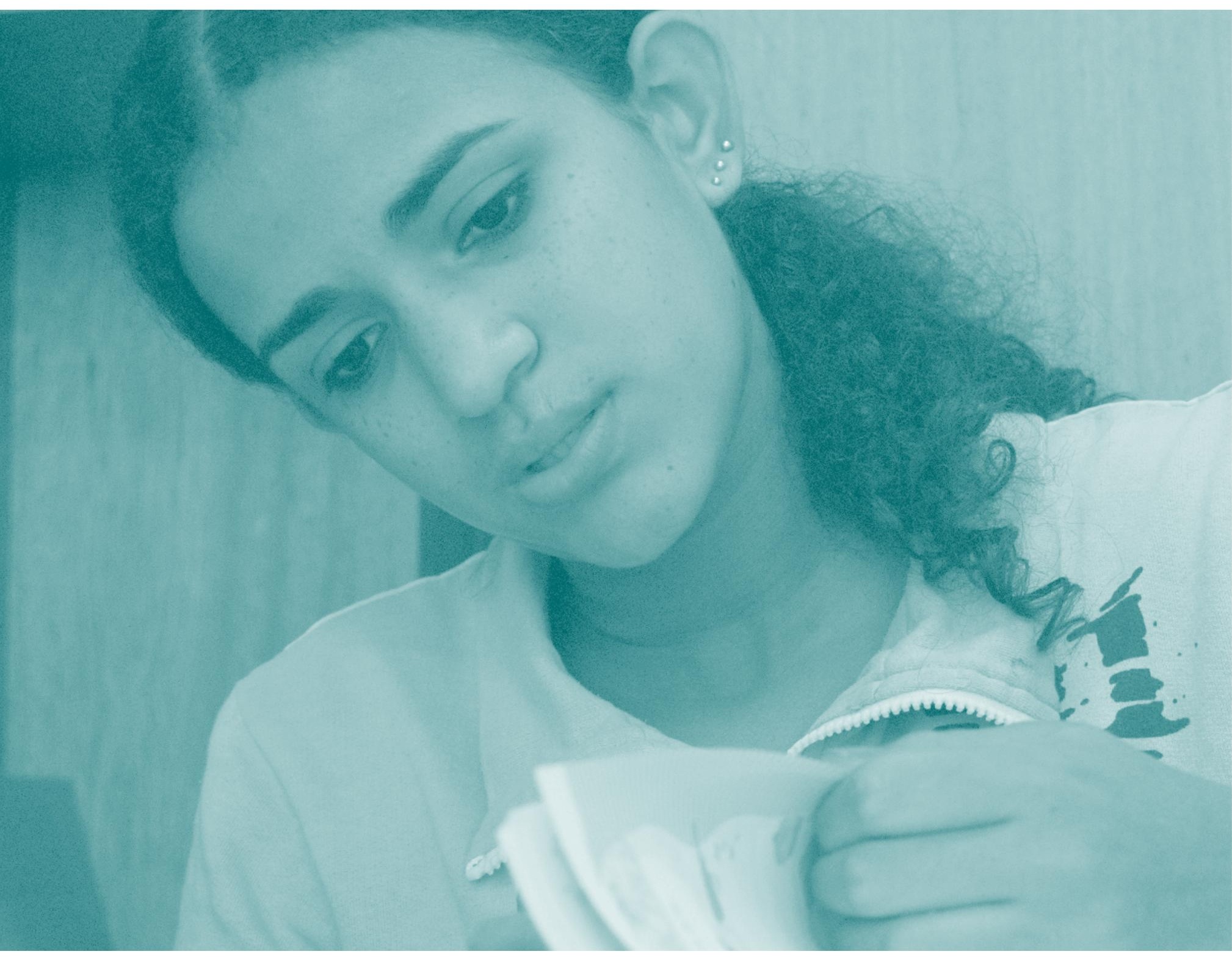

58 